\title{
Acknowledgments
}

Both authors owe a lifelong debt of gratitude to Miss Ima Hogg for introducing us to the pleasures of collecting and studying Texas furniture. Even though she has been gone for more than thirty-five years, this book is as much her spiritual legacy as it is our work. It could not have been written without her pioneering research and inspiration so many years ago.

We would like to thank Dr. Don Carleton, executive director of the Dolph Briscoe Center for American History at the University of Texas at Austin, and the Center's individual donors to this project, who are listed on a separate page of this book, for making our research, the photography, and the publication of this book possible.

We would like to thank the owners of the pieces of furniture illustrated here for graciously allowing us to disrupt their lives and their homes while photographing their furniture, and to express our appreciation to photographer J. B. Saucedo for his technical skill and his cheerful willingness to photograph furniture under difficult conditions.

We are especially grateful to the late Peter C. Marzio, director of the Museum of Fine Arts, Houston, for providing both assistance with photography in Houston and photographs of objects in the Bayou Bend Collection, and to Marise McDermott, president and chief executive officer of the Witte Museum in San Antonio, for providing assistance with photography in San Antonio.
The following people were especially helpful to the authors on their research trips across the state, providing both critical information and hospitality: Linda Anderson, Wayne Bell, James Clark, Don Chipman, Frank de la Teja, Linda Dietert, Frank Faulkner, Kenneth Hafertepe, David Hartmann, Boo Hausser, William J. Hill, Corbett Holmgreen, Allison Holmgreen Hughes, Hobart Rutherford Key, Charlotte Kroll, Jeff Merrell, Michael C. Miller, Robert Oliver, Maria Watson Pfeiffer, Lorene Riedel, Cam and Figgi Rosengren, George Russell, John Sauls, Helen Schupbach, William Seale, Glenn Treibs, and Glenwood Vernon. We are grateful to all of them, and to the many others-local librarians, county clerks, antiques dealers, and descendants of cabinetmakerswho took the trouble to answer what must have seemed like hundreds of pointless questions in order to provide us with the many small facts that went into the making of this book. Special thanks to Texas Parks and Wildlife Department staff.

Finally, we would like to express our appreciation to Dedie Uunila Taylor for proofreading our manuscript several times, and to our editors, Allison Faust and Kathy Bork at the University of Texas Press, and Holly Z. Taylor at the Dolph Briscoe Center for American History, for their ability to make an exacting task also a pleasurable one.

L.T./D.B.W

Fort Davis and Houston, March 2011 
THIS PAGE INTENTIONALLY LEFT BLANK 


\section{Texas Furniture}

VOLUME 2 


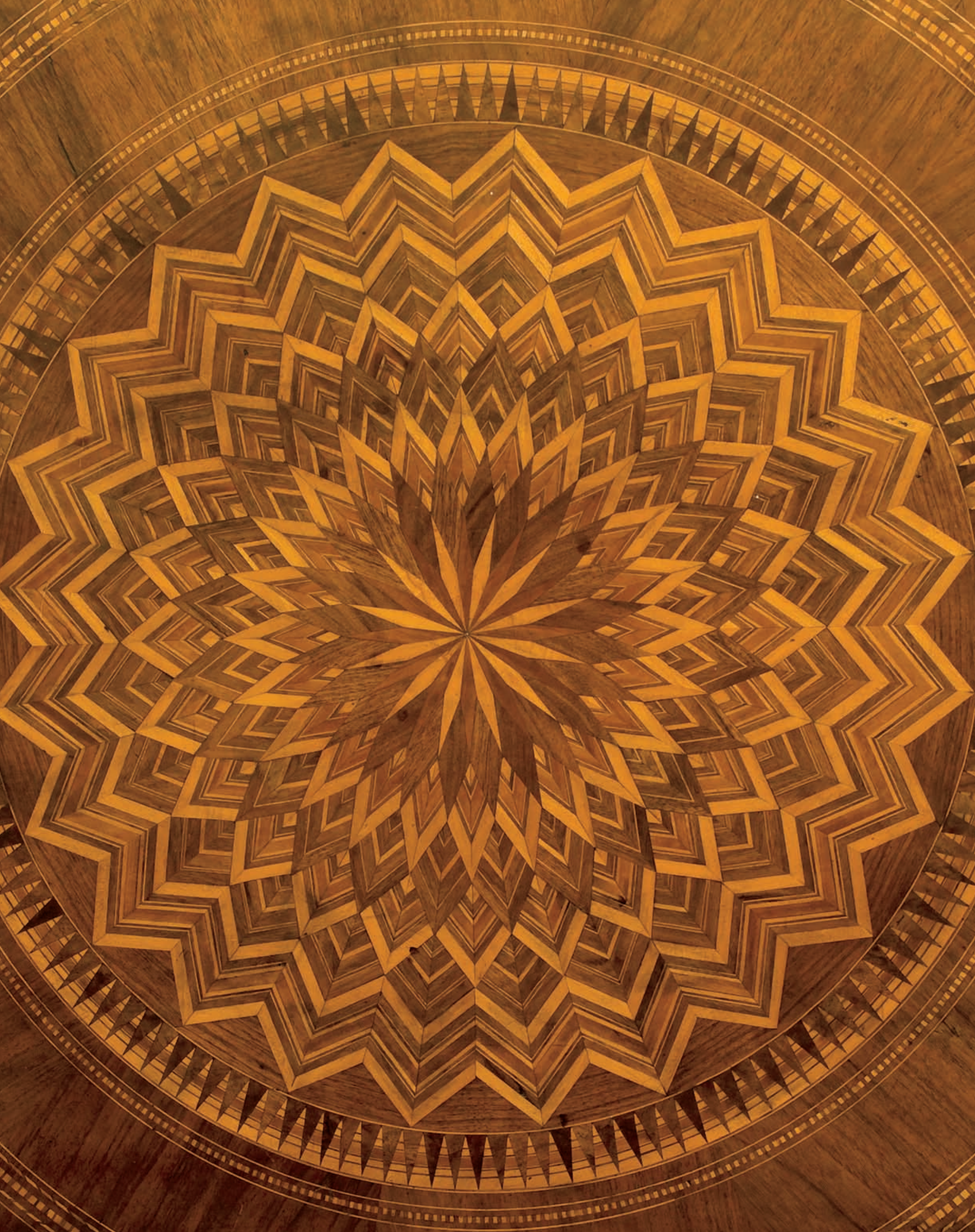

